\title{
FILTRATION EFFICIENCY OF SURGICAL AND FFP3 MASKS AGAINST COMPOSITE DUST
}

Sebastian Breul ${ }^{1}$, Kirsten L. Van Landuyt ${ }^{2}$, Franz X. Reichl ${ }^{1}$, Christof Högg ${ }^{1}$, Peter Hoet $^{3}$, Lode Godderis ${ }^{3,4}$, Bart Van Meerbeek ${ }^{2}$, Stevan M. Cokic ${ }^{2}$

${ }^{\text {I }}$ Department of Conservative Dentistry and Periodontology, University Hospital, LMU Munich, Munich, Germany

${ }^{2}$ KU Leuven (University of Leuven), Department of Oral Health Sciences, BIOMAT \& UZ Leuven (University Hospitals Leuven), Dentistry, Leuven, Belgium

${ }^{3}$ Centre for Environmental and Health, Department of Public Health and Primary Care, KU Leuven (University of Leuven), Leuven, Belgium

${ }^{4}$ IDEWE, External Service for Prevention and Protection at Work, Heverlee, Belgium

Running title: Mask protection from composite dust

\section{Corresponding author:}

Kirsten L. Van Landuyt, KU Leuven BIOMAT, Department of Oral Health Sciences, KU

Leuven, Kapucijnenvoer 7, B-3000 Leuven, Belgium. TEL: +32-16-33.27.45, E-mail:

kirsten.vanlanduyt@kuleuven.be 
ABSTRACT: The aim of this study was to investigate the protection efficiency of two types of face masks against composite dust and to characterize the particles that penetrated through the masks. Composite dust was created by grinding a commercial nano-filled composite in a plexiglass box without using water cooling or high vacuum evacuation to obtain a worst-case exposure. Dust particles were collected using a personal inhalable aerosol sampler (IOM) fixed inside a custom-made phantom head. A surgical and a FFP3 (filtering facepiece) mask were tested, whereas the situation without mask served as control. The IOM sampler contained a cassette with two filters to collect large inhalable $(4-100 \mu \mathrm{m})$ and respirable dust particles $(<4 \mu \mathrm{m})$. The amount of particles was determined gravimetrically by weighing filters before and after composite grinding, and further characterized by electron microscopy. Particle collection for both inhalable and respirable dust was the highest when no mask was used, and the lowest with the FFP3 mask. Different sizes and shapes of particles were observed with the largest particles $(>1 \mu \mathrm{m})$ seen when no mask was applied, whereas only nanoparticles could be detected when either type of face masks were applied. Even though FFP3 masks showed a higher filtration efficacy than surgical masks of the inhalable dust fraction, penetration of a small respirable particle fraction was inevitable for both masks.

KEYWORDS: protection device, nanoparticle, composite dust, dental (surgical) mask, FFP3 respirator, TEM

Kirsten L. Van Landuyt, KU Leuven BIOMAT, Department of Oral Health Sciences, KU

Leuven, Kapucijnenvoer 7, B-3000 Leuven, Belgium.

e-mail: kirsten.vanlanduyt@kuleuven.be 
Researchers have recently expressed concerns that there may be a health risk connected to the use of nanoparticles in composites $(1,2)$ as dental personnel may inhale aerosolized composite dust while shaping and polishing new, or removing old composite restorations $(3,4)$. Previously, it has been revealed that during abrasive procedures, respirable dust particles $(<4 \mu \mathrm{m})$ including a high percentage of nano-sized particles $(<100 \mathrm{~nm})$ are released in the breathing area of both patients and dental personnel (5).

Inhalation of respirable particles and in particular nanoparticles has been associated with adverse systemic and respiratory health effects such as increased respiratory symptoms and infections, decreased lung function, and altered mucocilliary clearance (6-8). These adverse effects of nanoparticles are explained by their unique physicochemical properties such as their small size, large and active surface, solubility, shape and aggregation. These properties make them much more reactive compared to larger particles with the same chemical composition (9). Even though first toxicological evidence is relatively reassuring, it may, however, be advisable to prevent inhalation of composite dust. Despite mild effects in human bronchial epithelial cells $(10,11)$ or alveolar macrophages (12), composite dust has been shown to be capable of inducing biological effects in vitro. Composite dust is also capable of releasing monomers (13), and theoretically, monomers could emanate from inhaled dust particles (13). Some reports have shown that in the last decade there has been an increase of respiratory problems such as occupational asthma and respiratory irritation among dental personnel (14), although the cause has not yet been determined.

Standard occupational protection protocols against bloodborne diseases prescribe the use of surgical masks, gloves, safety glasses or face shield to prevent transmission of infectious agents. The use of dental masks, also known as surgical or procedure masks, have specifically been advocated by the American Dental Association (ADA) and Centers for Disease Control and Prevention (CDC) in order to reduce the incidence of acute and chronic respiratory infections 
in both the patient and the healthcare personnel $(15,16)$. Even though it is generally accepted that surgical masks serve as a protection against bioaerosols transferred from a patient to a wearer and vice versa, studies have shown that only the patient and not the wearer remains protected in this way $(17,18)$. The main weakness of this type of mask is the lack of sealing between the face of the dentist and the mask, which results in incomplete protection. There has been an ongoing debate regarding their filtration efficiency as it has been shown that penetration occurs mainly between edge of the mask and the face, instead through filter medium (19). In contrast, air-purifying particulate respirators or so-called FFP masks ('filtering facepiece') are considered highly effective protective devices to reduce inhalation exposure to aerosols (20). Compared to surgical masks, respirators are designed to provide a tight seal with the face of the wearer, and must meet rigorous standards including high filtration efficiencies. Although face respirators have not been officially introduced in the dental practice, they may prevent composite dust inhalation.

However, until now, there is no research available, in which the mask protection efficiency against airborne composite dust particles is investigated. Therefore, the main objective of this study was to investigate the protection efficiency of two different types of face masks (surgical mask and FFP3 mask) against composite dust. An FFP3 mask is a face respirator with 99\% filtration efficiency against $<0.3 \mu \mathrm{m}$ particles (21). Additionally, particles that were able to penetrate through the tested masks were characterized. The null hypothesis of this study was that neither type of mask protects against airborne composite dust. 


\section{MATERIAL AND METHODS}

\section{Composite material used}

Blocks of composite (Filtek Supreme XTE; 3M, Seefeld, Germany) (Table 1), of size $17.4 \mathrm{~mm}$ x $5.4 \mathrm{~mm}$ x $1.6 \mathrm{~mm}$ were prepared in a metal mold following manufacturer's instructions. After application in the metal mold, the unpolymerized composite was covered with a glass plate to avoid the formation of an oxygen layer and subsequently polymerized for 40 s with a light lamp (Bluephase 20i, High power mode; Ivoclar-Vivadent, Schaan, Liechtenstein) with an output $>1000 \mathrm{~mW} \mathrm{~cm}^{-2}$ and wavelength $385-515 \mathrm{~nm}$. Since the diameter of the light probe was $10 \mathrm{~mm}$ (i.e., smaller than the length of the sample), each segment of the sample was polymerized for 40 s until all parts were adequately cured (approximately 3 curings per sample). Each time the lamp tip was held as close as possible to the covering glass plate.

\section{Generation of composite dust}

Experiments were carried out in a custom-made plexiglass box ( $270 \times 270$ x $420 \mathrm{~mm})$ with two openings on each side enabling manipulation of the specimen and the bur (Fig.1). For each group, four blocks of composite $(n=4)$ were ground in an enclosed chamber, with a rough diamond dental bur (842314014; Komet, Lemgo, Germany, grain size $100 \mu \mathrm{m}$ ) in a red Kavo Intracompact red angled handpiece connected to an electric micromotor (EWL K9; Kavo, Biberach, Germany). Each composite sample was ground for 3 min to ensure that the same amount of particles was released for each replicate. After grinding, sampling continued for 10 min. For each composite block, a new bur and a new mask or a respirator were used.

\section{Mask challenge and collection of particles}

To test the efficacy of the masks, a mannequin head was made from gypsum, in which an IOM personal inhalable aerosol sampler was fixed at the area of the nose and mouth, approximately 
$15 \mathrm{~cm}$ from the place where the dust was generated (Fig. 1). Adequate sealing of the sampler in the head was done using silicone and scotch tape (Tesa Extra Power Universal; Tesa, Hamburg, Germany) and it only allowed sampling of air in front of the mannequin's head. The sealing efficiency was confirmed using a bubble-producing liquid before the measurements. The sampler was attached to a personal sampling pump (Sidekick pump; SKC, Dorset, UK) calibrated to produce an inward airflow of 2 1/min using a calibration device (Defender 510; BIOS International, Butler, NJ, USA).

There were two test groups: i) one with a surgical mask (Standard earloop face mask 1826; 3M, St. Paul, MN, USA) and ii) one with an FFP3 mask (FFP3 Disposable Respirator 8835; 3M, Bracknell, UK) positioned on the mannequin head. To prevent incomplete sealing of the FPP3 mask, the edge of the mask was sealed with scotch tape (Tesa Extra Power Universal; Tesa). Measurements made in the absence of composite grinding served as the negative control and measurements made when grinding composite without application of a mask or respirator served as the positive control. The IOM sampler contained a cassette with two filters: i) a polyurethane foam disk (Multidust foam disc, 225-772; SKC) and ii) a glass fiber filter with a pore size of $1 \mu \mathrm{m}(225-702 ; \mathrm{SKC})$. The two filters allowed separation of the particles by size, as the large inhalable size particles $(>4-100 \mu \mathrm{m})$ deposited on the foam disk and the small respirable particles $(<4 \mu \mathrm{m})$ passed through the foam filter and were collected on the glass fiber filter. Prior to collecting particles, the filters were acclimatized overnight and subsequently weighted on a microbalance (ME; Sartorius, Göttingen, Germany). The amount of collected particles was expressed in $\mathrm{mg} / \mathrm{m}^{3}$ and calculated following formula:

$$
\text { Dust concentration }\left(\mathrm{mg} / \mathrm{m}^{3}\right)=\frac{\text { mass of particles collected on the filter }}{\text { average pump flow } * \text { time of sampling }}
$$

Filtering efficiency of both surgical mask and FFP3 respirator was expressed in terms of the weight percentage of the collected inhalable or respirable particle fraction with respect to the 
control situation where no mask was applied (17). Filtration efficiency of the tested masks was calculated according to following formula:

$$
\text { Filtration efficiency }(\%)=\left(1-\frac{\text { weight gain with mask }}{\text { weight gain without mask }}\right) \times 100
$$

\section{Characterization of composite dust}

The size and shape of the collected particles was characterized by transmission electron microscopy (TEM) (JEM-1200 EX II; JEOL, Tokyo, Japan) at a voltage of 80kV. A copper formvar-coated TEM grid (FF200H-Cu-50; Electron Microscopy Sciences, Hatfield, PA, USA) was attached to the bottom (plastic mash) of the IOM cassette instead of a glass filter. Particle collection was carried out in the same way as previously described, after which the TEM grids were removed and stored until analysis.

In order to determine the particle-size distribution of the penetrated particles through the surgical mask and FFP3 respirator, around 400 counted particles in TEM images were statistically analyzed (22). More precisely, around 200 particles smaller than $100 \mathrm{~nm}$ and 200 particles larger than $100 \mathrm{~nm}$ were evaluated at a magnification of $60,000 \times$ and $20,000 \times$, respectively (with respective scale of 1 and $5.8 \mathrm{~nm} /$ pixel). Particle diameter was based on the minimal Feret diameter.

\section{Statistical analysis}

Differences between weights of collected inhalable and respirable dust fractions of composite dust in all three conditions (no mask, surgical mask and FFP3 respirator) were statistically analyzed by the Kruskal-Wallis test and Mann-Whitney test. The same tests were used to statistically evaluate differences in filtration efficiencies between the surgical and FFP3 masks. All tests were performed at a significance level of $\alpha=0.05$. 


\section{RESULTS}

\section{Gravimetrical analysis of inhalable and respirable dust fraction}

Gravimetrical analysis showed that the inhalable fraction was in general much higher than the respirable dust fraction (Table 2). The highest mass of inhalable particles was collected when no protection was used (positive control), and significantly more inhalable particles went through the surgical mask $\left(29 \mathrm{mg} / \mathrm{m}^{3}\right)$ compared to the FFP3 mask $\left(8.8 \mathrm{mg} / \mathrm{m}^{3}\right)$. Similar observations were made for the respirable dust fraction, with the highest penetration when no mask was applied to the mannequin head $\left(5.29 \mathrm{mg} / \mathrm{m}^{3}\right)$. The FFP3 respirator $\left(1.48 \mathrm{mg} / \mathrm{m}^{3}\right)$ filtered respirable dust slightly better the surgical mask $\left(1.9 \mathrm{mg} / \mathrm{m}^{3}\right)$, but this difference was not statistically different.

The filtration efficiency of the surgical mask was significantly lower for both inhalable and respirable dust fractions (91.9\% and $63.6 \%$ respectively), compared to the FFP3 respirator whose filtration efficacy was $96.8 \%$ for the inhalable and $71.7 \%$ for the respirable dust fraction (Table 2).

\section{Electron microscopy characterization}

Ultramorphological analysis by TEM confirmed that many particles varying both in size and shape were released during grinding of dental composites, and this was particularly manifest in the group where no mask was applied to the mannequin head. The size and shape of the particles also differed according to the type of protection applied. Larger particles ( $>1 \mu \mathrm{m})$ were more often seen when no protection measures were applied, and smaller submicron and nano-sized particles were predominately observed when a surgical or FFP3 mask was used (Fig. 2). The larger particles consisted of dental fillers held together in the resin matrix. Furthermore, single nano-filler particles could be observed in all three tested conditions. The weighted average size of the collected particles ranged between 40-50 nm (Table 3, Fig. 3). 


\section{DISCUSSION}

In order to demonstrate the filtering efficiency of surgical masks the Food and Drug Administration (FDA) has recommended two types of tests including evaluation of particulate filtration efficiency of un-neutralized aerosol ( $0.1 \mu \mathrm{m}$ latex spheres $)$ and evaluation of bacterial filtration efficiency against un-neutralized Staphylocococus aureus $(3 \pm 0.3 \mu \mathrm{m})$ (16). Compared to surgical masks, respirators must meet rigorous certification, which is often differently regulated for USA and European countries. In the USA, different types of respirators (N, R and P series) must be certified by The National Institute for Occupational Safety (NIOSH, Title 42 CFR Part 84) with the minimum filtration efficiencies of $95 \%, 99 \%$, and $99.7 \%$ against particles $<0.3 \mu \mathrm{m}$. On the other hand, respirators used in Europe, such as FFP1, FFP2 and FFP3, are certificated by Conformité Européenne (CE) in order to meet filtration efficiencies of $80 \%, 94 \%$ and $99 \%$, respectively. Both NIOSH and CE follow different protocol for approval

Just recently, it became clear that while performing some routine procedures like shaping, polishing or removing dental composite fillings, dental personnel could be exposed to ultrafine composite dust (23). However, information regarding the efficiency of current protection measures against these particles is still missing. Therefore, the main aim of this study was to evaluate the protection efficacy of surgical masks as one of the most frequently used protection devices in dental practice. Interestingly, the results from this study demonstrate that both the surgical mask and the FFP3 respirator can protect against composite dust to a certain degree, but also that they are to some extent penetrable, especially to small respirable composite particles. The null hypothesis can thus be partially rejected. More research is certainly warranted to investigate possible exposure and mask efficiency in dental practice.

The experimental set-up was designed to evaluate the penetration level of airborne composite dust through surgical masks and FFP3 respirators. Therefore, the exposure circumstances in our 
experiment were set up as a worst-case exposure, by producing dust in a small box. In order to produce composite dust, composite samples, whose size corresponded to large MOD fillings, were ground with a rough diamond bur in a red angled handpiece according to a procedure similar to composite filling removal in dental practice. Even though finishing and polishing of composite restorations can take several minutes in a dental office, it is unlikely that the dental personnel will be exposed to such high amounts of dust on a daily basis as produced during extensive composite grinding for $3 \mathrm{~min}$. Also, during the development of our set-up, this grinding period was found optimal for two specific reasons. First, during this period a sufficient amount of particles could be collected on both sponge and fiber glass filters and subsequently gravimetrically quantified. Second, the amount of particles generated would not saturate the first sponge filter intended for collection of larger inhalable particle fraction and block the penetration of smaller respirable particles towards the fiber glass filter. Moreover, in our set-up there was no water spray applied during grinding nor high vacuum suctioning. Even though it is advisable to always use water spray, some procedures are carried out without (for example on front teeth, when the use of shaping disks or when visibility is hampered).

In a recently published study the influence of water spray on the release of respirable, and in particular, nano-sized particles during rotary manipulation of composites has been evaluated and the study showed that even though water spray could significantly decrease the concentration of released nanoparticles, this amount was still many times higher than the background control (24). On the other hand, it is still not clear whether other factors, such as high vacuum systems or even different abrasive tools such as tungsten carbide burs, stones, abrasive coated abrasive disks, rubber cups, points or wheels, can influence dust production. Even though other instruments were not tested in this study, it could be expected that other instruments would to some extent lead to emission of different amounts and different sizes of particles. In the study by VAN LANDUYT et. al. (23), the released particles were measured in the 
dental office during the placement of composite restoration and clinical measurements revealed clearly distinguishable peak moments of high concentrations of composite dust upon contouring with diamond bur without water-cooling and upon finishing with rough polishing disks (coarse and medium grid, Sof-Lex disks; 3M ESPE) (23). Also, in another study which focused on the release of nanoparticles during aesthetic treatment of incisors, the highest concentration was measured while the restoration was shaped using a rough polishing disk (5). Moreover, it is plausible that operating at a lower speed will decrease the emission of nanoparticles. Therefore, it would be interesting to investigate the influence of all these factors (tool surface roughness, operating speed, vacuum system) on the release of composite dust in order to better understand these factors, which might then allow us to adjust our polishing techniques and have the highest effect with the lowest dust emission.

The main strength of this study lies in the fact that airborne composite dust was collected with an individual personal inhalable aerosol sampler (IOM sampler), which is able to separate and collect particles according to their size. The inhalable dust fraction (between 4 and $100 \mu \mathrm{m}$ ), which is typically deposited in the upper compartment of the respiratory tract after inhalation, was collected by the first sponge filter, and the respirable dust fraction $(<4 \mu \mathrm{m})$ representing particles, which are deposited in the deeper lung compartments, were trapped on a glass fiber filter with the pore size of $1 \mu \mathrm{m}$. By weighing each filter before and after dust collection, the amount of both dust fractions that penetrated through the masks could be determined. The IOM sampler shows a huge advantage compared to other exposure measuring devices, since it can measure the exposure to particles with varying size, both large and small, which was the initial intention of this study. Moreover, this is considered the first study to evaluate the protection efficiency of masks against composite dust. On the other hand, since the sampling included both very small and large particles, the weight and thus calculated weight concentration would mainly be determined by the large ones. For this reason, it was difficult to make a distinction 
within the respirable dust fraction range, particularly between micron, submicron and nanoparticles. Therefore, the future research should focus on the measuring the exposure to small submicron and nano-sized particles using different evaluation techniques and determining particle number and size concentration.

Regardless of differences in design, both masks depend on mechanical filtration, where particulate matter adheres to the filter fibers either by interception, inertial impaction, diffusion, gravitational settling or electrostatic attraction (25). In polymorphic dust, such as composite dust, which consists of particles of various sizes, the collection efficiency is usually determined by a combination of all four mechanisms. However, it is generally accepted that interception and impaction are responsible for collection of larger particles while the smaller particles are predominately collected by diffusion (26). As expected, both surgical and FPP3 protection devices were able to block a large part of the inhalable (91.96\% and 96.82\%, respectively) and respirable dust particles ( $63.67 \%$ and $71.74 \%$, respectively) compared to the positive control where no protection measures were applied. It is important to note that masks were challenged with particle concentrations that exceeded manyfold the proposed threshold limit value of 4 $\mathrm{mg} / \mathrm{m}^{3}$ for inhalable dust and $0.3 \mathrm{mg} / \mathrm{m}^{3}$ for respirable dust fraction (27). It is unlikely that dental personnel are exposed to such high amounts of dust in the dental clinic on a daily basis, but nevertheless this experiment was designed to mimic the worst-case scenario and thus these results should be interpreted accordingly. However, it is worth noting that threshold limit values are not globally accepted and they will be different in USA or even in different countries of the EU. Moreover, there is unfortunately still no official legal binding framework concerning the specific limit of nanoparticles (28). The reason for this is that there are still numerous technical challenges to overcome, such as the lack of standardized instrumentation and sampling protocols for nanoparticle measurements (29), difficulties to reach a consensus on a metric system (30) for nanoparticles and lack of clear correlation of an exposure-response relationship 
(31). Just recently, Schmalz et al. (2) have calculated that if each day approximately 10 composite fillings are placed, the dentist/dental personnel will be exposed to approximately 20 $\mu \mathrm{g}$ of nanoparticles on a daily basis. Some agencies such as the German Agency for occupational safety (Bundesinstitut für Arbeitsschutz und Arbeitsmedizin) have proposed that the maximum acceptable nanodust concentration in the working environment should be in between $110-190 \mu \mathrm{g} / \mathrm{m}^{3}$ (2). Knowing that daily air uptake according to ISO 10993-17 is 10 $\mathrm{m}^{3}$, the daily acceptable dose of nanoparticle exposure should be in between 1100-1900 $\mu \mathrm{g}$, which is way above what is expected to be released during abrasive processing of dental composite (32).

As expected, surgical masks provided less protection than FFP3 respirators. Surgical masks are not equipped with a filtering medium that can reduce the penetration of airborne particles, as they are designed to block splatter and bioaerosols that can carry various types of microorganisms, viruses and fungi (33). Currently, many researchers are debating the real protection level of surgical masks as it has been shown that their filter efficiency can range from 4 to $90 \%$ (34-36). Even though there are two particle penetration pathways defined (through face seal leakage and through filter medium), studies show that the main particle penetration, especially of submicron particles, must be ascribed to the lack of face sealing (30-40\%) (18). This does not come as a surprise since surgical masks should only comply with standards on fluid resistance, differential pressure, flammability and filtration efficiency, whereas the fit of the mask on the face is not evaluated. In contrast to surgical masks, the design of FFP3 respirators provides a tight face seal (34). As it was difficult to ensure that the seal was complete on the gypsum mannequin head, tape was used to ensure complete sealing of the mask to the head. In ideal circumstances, an FFP3 respirator should be sealed by tight skin contact, but it is possible that in clinic, this cannot always be obtained. In our study, we, did not account for such 
an eventuality: by sealing our FFP3 respirator by tape, we assumed the ideal situation, where air only can pass through the filtering medium.

Nevertheless, the filtration efficiency of FFP3 respirators against small respirable particles was $71.74 \%$, which implies that around $30 \%$ of the released particles still could pass the FFP3 mask. This may be attributed to the fact that composite dust consists of many nano-sized particles $(<100 \mathrm{~nm})$ and all face respirators have been tested with the most penetrable particle size of $\approx 300 \mathrm{~nm}$. The penetration level of respirable dust was even higher for surgical masks (40\%), but the difference was not statistically significant. Additionally, it should be borne in mind that this relatively low efficiency of FFP3 respirators $(\approx 70 \%)$ against respirable particles could also be attributed to the methodological difference between our set up and the one proposed by NIOSH, which includes using larger box (chamber) preventing forced agglomeration, higher sampling air flow, lower exposure concentration and more sophisticated measurement instruments (21). On the other hand, the strength of our set-up lies in the fact that the filtration efficiency of surgical masks and respirators was tested using composite dust directly produced by grinding composite material in the same manner as during the placement of a composite restoration. Using the same particle form for the penetration analysis can be critical knowing that some studies have already drawn attention to the significant influence of the particle and/or filter charge on the penetration level through the masks and respirators (37). Penetration of some standard particles such as spherical $\mathrm{NaCl}$ particles proposed by NIOSH or polystyrene latex particles proposed by FDA do not completely resemble the complex morphology of composite dust. Nevertheless, even though FFP3 masks are specifically designed to protect against airborne particulate matter, so far, they have not been introduced into dental practice. As this study can be considered as a first screening of the efficiency of masks, future research studies should focus on the improvement of the set-up so it could closer meet the NIOSH testing regulations. 
The TEM characterization of airborne particles confirmed that predominately nano-sized particles penetrated through both the surgical mask and FFP3 respirator, even though particles of different sizes and shapes could be seen. Furthermore, it was confirmed that these particles consisted of small pieces of composites held together by dental resin. These findings closely correlate with the results on filtration efficiency as it is clear that the inhalable dust fraction is blocked by both types of masks, whereas the filtration efficiency for small respirable dust is rather lower. Transmission electron microscopy is a sensitive technique to visually detect and analyze nanoparticles that are difficult to measure gravimetrically as they practically do not have any mass. Nano-sized particles usually appear aggregated on the grid but so far it is not clear if agglomeration happens on the grid or before in the air. In the respiratory system, particles typically also aggregate after inhalation (38).

The evaluation of morphology and particle size distribution was determined by a TEM image analysis method, which was selected for specific reasons. First, the main strength of this method is that it includes a broader particle size range $(<100 \mu \mathrm{m})$ compared to other more sophisticated and more expensive techniques where the particle size range is mostly limited to particles below $1 \mu \mathrm{m}$. Second, particles could be directly collected on the TEM grid from the air during grinding composite sample, which allowed analyzing particle size and morphology at the same time. However, it is important to understand that this technique is considered to be an indirect method as the particle size distribution is based on a specific particle number, which is subsequently applied to the whole sample. Therefore, these results should be taken with care and combined with other appropriate techniques. Accordingly, TEM analysis confirmed that the weighted average size of particles (which was not influenced by a minority of extremes) that penetrated through the masks was between 40 and $60 \mathrm{~nm}$, which corresponds to the results of previous studies which also employed other techniques $(5,13,24)$. The diameter percentiles D10, D50 and D90 were calculated to express the particle size distribution. Furthermore, the modal value, 
which represents the size of the most frequently encountered particles, was in the range of 12$17 \mathrm{~nm}$, which corresponds to the size of $\mathrm{SiO}_{2}$ filler particles $(5-20 \mathrm{~nm})$ added to the composite by the manufacturer (Table 1).

Overall, this study provides new insights on the level of protection of surgical masks and FFP3 respirators against inhalable and respirable composite dust. Within the limitations of our study, which was set up as a worst-case exposure experiment (high concentrations of air-borne composite dust) with optimal use of the masks (perfect sealing of the FFP3 mask), the results showed that both types of masks provided protection against composite dust, even though the filtration efficiency was much lower for ultrafine respirable dust than expected. For this reason, dentists might not completely be protected from composite dust during abrasive manipulation of composite materials. Future research should focus more on the evaluation of particle exposure and protection measures in clinical conditions.

\section{ACKNOWLEDGMENTS}

This research was supported by the Research Foundation-Flanders (G.0884.13 and KAN2014 1.5.162.14). We would like to thank the manufacturers for generously providing the commercial composites.

CONFLICT OF INTERESTS: The authors declare that they have no conflict of interest. 


\section{REFERENCES}

1. JANDT KD, SigUSCH BW. Future perspectives of resin-based dental materials. Dent Mater. 2009;25:1001-1006.

2. Schmalz G, Hickelb R, VAn LANDUYT KL, FranZ-XAVER Reichl. Nanoparticles in dentistry. Dent Mater. 2017;33:1110-1126.

3. NAYEBZAdeh A, STANGEl I, DUfRESNE A. Risk of respiratory exposure of dental personnel to amalgam alternatives. Sci Total Environ. 2000;247:33-39.

4. COLLARD SM, VOGEL JJ, LADD GD. Respirability, microstructure and filler content of composite dusts. Am J Dent. 1991;4:143-151.

5. Van Landuyt KL, Hellack B, Van Meerbeek B, Peumans M, Hoet P, Wiemann M, KunlBusch TAJ, AsBACH C. Nanoparticle release from dental composites. Acta Biomater. 2014;10:365-374.

6. GWinn MR, Vallyathan V. Nanoparticles: Health effects - Pros and cons. Environ Health Perspect. 2006;114:1818-1825.

7. SiMKÓ M, MATTSSON MO. Risks from accidental exposures to engineered nanoparticles and neurological health effects: A critical review. Part Fibre Toxicol. 2010;7:1-15.

8. BAKAND S, Hayes A, DeChSAKUlthorn F. Nanoparticles: A review of particle toxicology following inhalation exposure. Inhal Toxicol. 2012;24:125-135.

9. OBERDÖRSTER G, OBERDÖRSTER E, OBERDÖRSTER J. Nanotoxicology: An emerging discipline evolving from studies of ultrafine particles. Environ Health Perspect. 2005; 113:823-839.

10. Cokic SM, Hoet P, Godderis L, Wiemann M, Asbach C, Reichl FX, De Munck J, VAn MeERBeEK B, VAn LANDUYT KL. Cytotoxic effects of composite dust on human bronchial epithelial cells. Dent Mater. 2016;32:1482-1491.

11. Cokic SM, Ghosh M, Hoet P, Godderis L, VAn Meerbeek B, Van LanduYt KL. Cytotoxic and genotoxic potential of respirable fraction of composite dust on human bronchial cells. Dent Mater. 2020;36:270-283.

12. Van Landuyt KL, Cokic SM, Asbach C, Hoet P, Godderis L, Reichl FX, Van MEERBEEK B, VENNEMANN A, WIEMANN W. Interaction of rat alveolar macrophages with dental composite dust. Part Fibre Toxicol. 2016;13:1-13.

13. Cokic SM, Duca RC, Godderis L, Hoet PH, Seo JW, Van Meerbeek B, Van LANDUYT KL. Release of monomers from composite dust. J Dent. 2017;60:56-62.

14. Pirrilä P, Hodgson U, Estlander T, Keskinen H, SAalo A, Voutilainen R, KANERVA L. Occupational respiratory hypersensitivity in dental personnel. Int Arch Occup Environ Health. 2002;75:209-216.

15. AMERICAN DENTAL ASSOCIATION COUNCIL ON SCIENTIFIC AFFAIRS AND AMERICAN DENTAL AsSOCIATION CONCIL ON DENTAL PRACTICE. Infection Control Recommendations for the Dental Office and the Dental Laboratory. J Am Dent Assoc. 1996;127:672-80.

16. FOOD AND DRUG ADMINISTRATION (FDA). Guidance for Industry and FDA Staff Surgical Masks - Premarket Notification [510(k)] Submissions: Guidance for Industry and FDA. Maryland: Center for Devices and Radiological Health, 2003;1-13.

17. CheCChi L, MonteVecchi M, Moreschi A, Graziosi F, TAdDEI P, Violante FS. Efficacy of three face masks in preventing inhalation of airborne contaminants in dental practice. J Am Dent Assoc. 2005;136:877-882.

18. GRINSHPUn S A, HARUTA H, ENINGER RM, REPONEN T, MCKAY RT, LEE S-A. Performance of an N95 filtering facepiece particulate respirator and a surgical mask during human breathing: two pathways for particle penetration. J Occup Environ Hyg. 
2009;6:593-603.

19. BELKIN NL. Masks, barriers, laundering, and gloving: Where is the evidence? AORN J. 2006;84:655-664.

20. Batazy A, Toivola M, Reponen T, Zimmer A, Podgo A, Grinshrun SA. ManikinBased Performance Evaluation of N95 Filtering-Facepiece Respirators Challenged with Nanoparticles. Ann Occup Hyg. 2006;50:259-269.

21. RENGASAMY S, EIMER BC, SHAFFER RE. Comparison of nanoparticle filtration performance of NIOSH-approved and CE-marked particulate filtering facepiece respirators. Ann Occup Hyg. 2009;53:117-128.

22. ISO 13322-1:2014. Particle size analysis - Image analysis methods Part $1:$ Static image analysis methods. London: British Standards Publication (BSI), 2014;1-36.

23. Van landuyt KL, Yoshihara K, Geebelen B, Peumans M, Godderis L, Hoet P, VAN MEERBEEK B. Should we be concerned about composite (nano-)dust? Dent Mater. 2012;28:1162-1170.

24. Cokic SM, Asbach C, Munck J De, Van Meerbeek B, Hoet P, Seo JW, Van LANDUYT KL. The effect of water spray on the release of composite nano-dust. Clin Oral Invest. 2019; in press.

25. HINDS WC. Aerosol technology: Properties, Behavior, and Measurement of Airborne Particles 2nd ed. New York: Wiley-Interscience Publication, 1999; 233-259.

26. Huang SH, Chen CW, Chang CP, Lai CY, Chen CC. Penetration of $4.5 \mathrm{~nm}$ to $10 \mu \mathrm{m}$ aerosol particles through fibrous filters. J Aerosol Sci. 2007;38:719-27.

27. DEUTSCHE FORSCHUNGSGEMEINSCHAFT. List of MAK and BAT Values 2018: Permanent Senate Commission for the Investigation of Health Hazards of Chemical Compounds in the Work Area. Report 54. Weinheim: Wiley, 2018;19-167.

28. MAYNARD AD, AITKEN RJ. Assessing exposure to airborne nanomaterials: Current abilities and future requirements. Nanotoxicology. 2007;1:26-41.

29. Asbach C, Kaminski H, Fissan H, Monz C, Dahmann D, Mulhopt S, Paur HR, Kiesling HJ, Herrmann F, Voetz M. Kuhlbusch TAJ. Comparison of four mobility particle sizers with different time resolution for stationary exposure measurements. $J$ Nanoparticle Res. 2009;11:1593-609.

30. HEAL MR, KUMAR P, HARRISON RM. Particles, air quality, policy and health. Chem Soc Rev. 2012;41:6606-30.

31. SAYES CM, REED KL, WARHEIT DB. Assessing toxicology of fine and nanoparticles: Comparing in vitro measurements to in vivo pulmonary toxicity profiles. Toxicol Sci. 2007;97:163-80.

32. ISO 10993-17:2002. Biological evaluation of medical devices - Part 17:

Establishment of allowable limits for leachable substances. Geneva: International Organization for Standardization (ISO), 2002;1-25.

33. BHUVANESWARI P. Aerosols - A Concern for Dentists. Res J Pharm Technol. 2014;7:938-941.

34. Oberg T, Brosseau LM. Surgical mask filter and fit performance. Am J Infect Control. 2008;36:276-82.

35. CoOper DW, Hinds WC, Price JM, WeKer R, YeE HS. Common materials for emergency respiratory protection: leakage tests with a manikin. Am Ind Hyg Assoc J. 1983;44:720-6.

36. Weber A, Willeke K, Marchloni R, Myojo T, McKay R, DONNElly J, LiebHaber F. Aerosol penetration and leakae characteristics of masks used in the health care industry. AJIC Am J Infect Control. 1993;21:167-73.

37. WAKE D, BROWN RC, TROTTIER RA, LIU Y. Measurements of the efficiency of respirator filters and filtering facepieces against radon daughter aerosols. Ann Occup 
Hyg. 1992;36:629-36.

38. Tang M, Zhang T, Xue Y, Wang S, Huang M, Yang Y, Minyu L, Hao L, Lu K, Pu Y. Dose dependent in vivo metabolic characteristics of titanium dioxide nanoparticles. J Nanosci Nanotechnol. 2010;10:8575-83. 


\section{TABLES}

Table 1: Composition of the dental composite.

\begin{tabular}{|c|c|c|c|c|c|}
\hline Composite & Manufacturer & Classification & $\begin{array}{l}\text { Resin } \\
\text { matrix }\end{array}$ & Filler & $\begin{array}{l}\text { Filler } \\
\text { loading }\end{array}$ \\
\hline $\begin{array}{l}\text { Filtek Supreme } \\
\text { XTE }\end{array}$ & $\begin{array}{l}\text { 3M ESPE, } \\
\text { Seefeld, } \\
\text { Germany }\end{array}$ & $\begin{array}{l}\text { Nano- } \\
\text { composite }\end{array}$ & $\begin{array}{l}\text { BisGMA, } \\
\text { BisEMA, } \\
\text { UDMA, } \\
\text { TEGDMA }\end{array}$ & $\begin{array}{l}\text { - } \mathrm{SiO}_{2}(20 \mathrm{~nm}) \\
\text { - } \mathrm{Zirconia-silica} \mathrm{clusters} \\
(0.6-1.4 \mu \mathrm{m}) \\
\text { with primary particles } \\
\text { of } 5-20 \mathrm{~nm}\end{array}$ & $\begin{array}{l}78.5 \text { wt } \% \\
59.5 \text { vol\% }\end{array}$ \\
\hline
\end{tabular}

Abbreviations: BisGMA: bisphenol A diglycidyl dimethacrylate; BisEMA: ethoxylated bisphenol A glycol dimethacrylate; UDMA: urethane dimethacrylate; TEGDMA: triethylene glycol dimethacrylate;

Based on information provided by the manufacturer. 
Table 2: Evaluation of the collected amount and filtration efficiency of inhalable and respirable composite dust without and with application of protection devices.

\begin{tabular}{|c|c|c|c|c|}
\hline & \multicolumn{2}{|c|}{$\begin{array}{l}\text { Total collected amount of particles } \\
\qquad\left(\mathrm{mg} / \mathrm{m}^{3}\right)\end{array}$} & \multicolumn{2}{|c|}{$\begin{array}{l}\text { Filtration efficiency of protection devices } \\
\text { (\%) }\end{array}$} \\
\hline & $\begin{array}{c}\text { Inhalable dust } \\
\text { fraction }(>4-10 \mu \mathrm{m})\end{array}$ & $\begin{array}{l}\text { Respirable dust } \\
\text { fraction }(<4 \mu \mathrm{m})\end{array}$ & $\begin{array}{c}\text { Inhalable dust } \\
\text { fraction }(>4-10 \mu \mathrm{m})\end{array}$ & $\begin{array}{l}\text { Respirable dust } \\
\text { fraction }(<4 \mu \mathrm{m})\end{array}$ \\
\hline $\begin{array}{l}\text { No } \\
\text { protection }\end{array}$ & $276.2 \pm 36.1^{\mathrm{a}}$ & $5.3 \pm 0.6^{a}$ & / & / \\
\hline $\begin{array}{l}\text { Surgical } \\
\text { mask }\end{array}$ & $22.5 \pm 8.7^{b}$ & $1.9 \pm 0.7^{b}$ & $92 \pm 2.3^{a}$ & $63.7 \pm 13.8^{a}$ \\
\hline $\begin{array}{l}\text { FFP3 } \\
\text { respirator }\end{array}$ & $8.8 \pm 1.8^{c}$ & $1.5 \pm 0.2^{\mathrm{bc}}$ & $96.8 \pm 0.3^{b}$ & $71.7 \pm 4^{a}$ \\
\hline
\end{tabular}

Average particle number concentration and standard deviation;

Different superscript letters depicts significant difference between protection devices for inhalable and respirable dust fraction independently; 
Table 3: Characterization of the particles by transmission electron microscopy. Minimum, maximum and weighted average sizes are shown, as well as representative diameters (D10, D50 and D90).

\begin{tabular}{lccccccc}
\hline & $\begin{array}{c}\text { Min } \\
(\mathbf{n m})\end{array}$ & $\begin{array}{c}\text { Max } \\
(\mathbf{n m})\end{array}$ & $\begin{array}{c}\text { Weighted average } \\
\text { size }(\mathbf{n m})\end{array}$ & $\begin{array}{c}\text { Modal value } \\
(\mathbf{n m})\end{array}$ & $\begin{array}{c}\text { D10 } \\
(\mathbf{n m})\end{array}$ & $\begin{array}{c}\text { D50 } \\
(\mathbf{n m})\end{array}$ & $\begin{array}{c}\text { D90 } \\
(\mathbf{n m})\end{array}$ \\
\hline $\begin{array}{l}\text { No } \\
\text { protection }\end{array}$ & 6 & 4088.74 & 46.93 & 12.04 & 7.75 & 13.23 & 55.38 \\
$\begin{array}{l}\text { Surgical } \\
\text { mask }\end{array}$ & 4.32 & 4327.7 & 54.08 & 12.4 & 15.06 & 32.84 & 55.71 \\
$\begin{array}{l}\text { FFP3 } \\
\text { respirator }\end{array}$ & 6 & 3465.24 & 42.23 & 16.82 & 10.26 & 19.51 & 41.09
\end{tabular}

Abbreviations: D10, percentile 10; D50, median; D90, percentile 90; 


\section{FIGURES}

\section{Figure 1:}

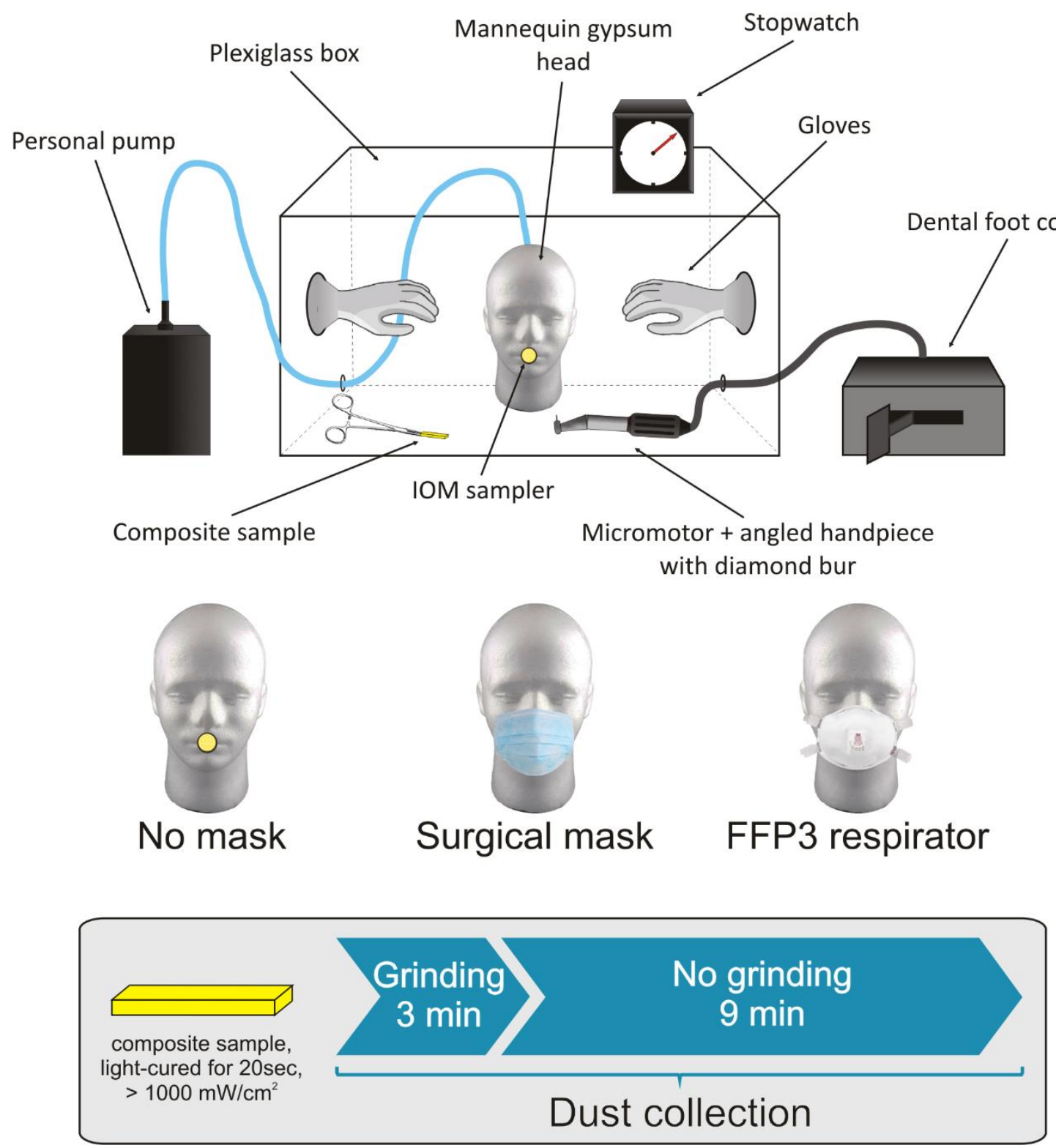


Figure 2:

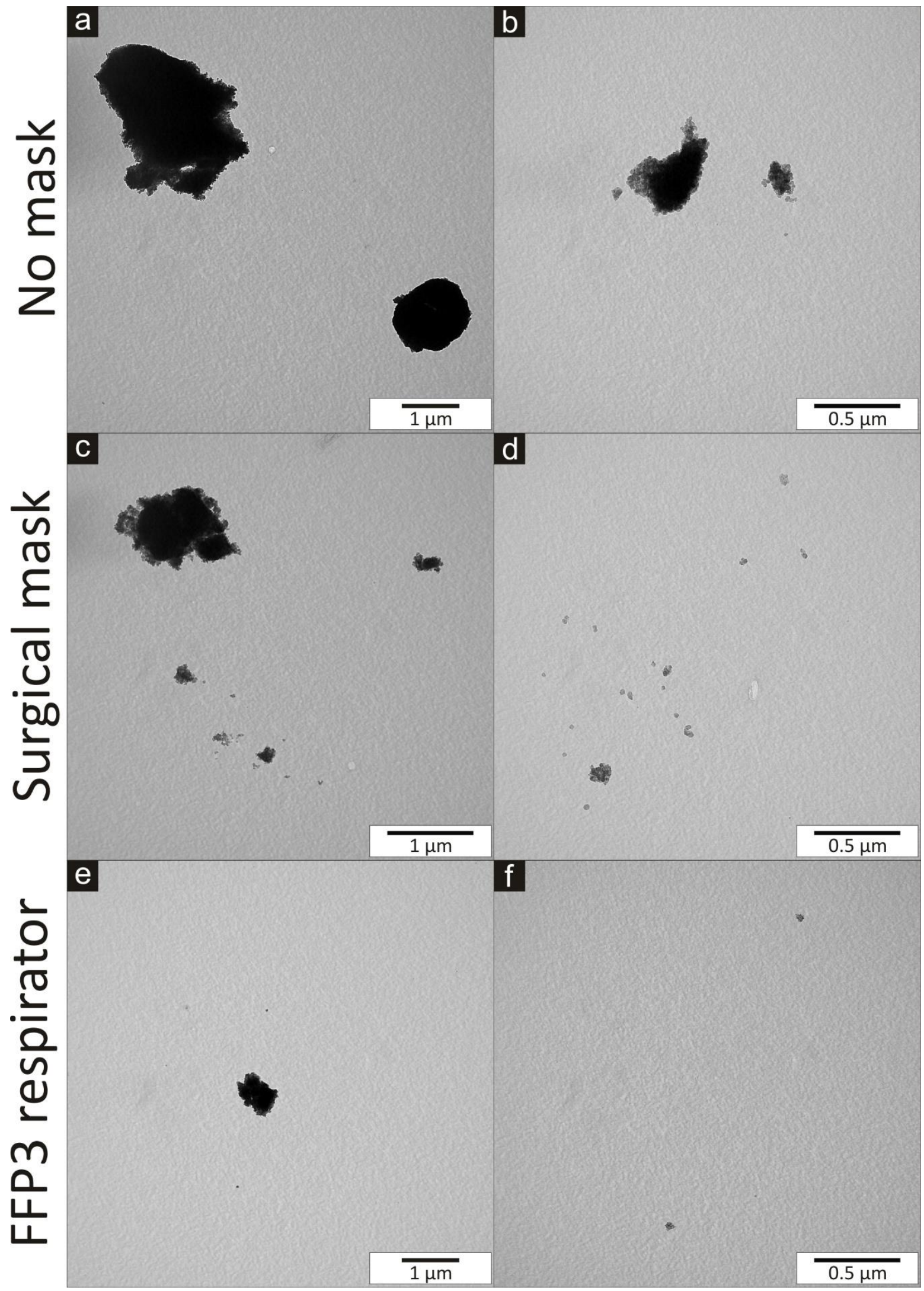


Figure 3:

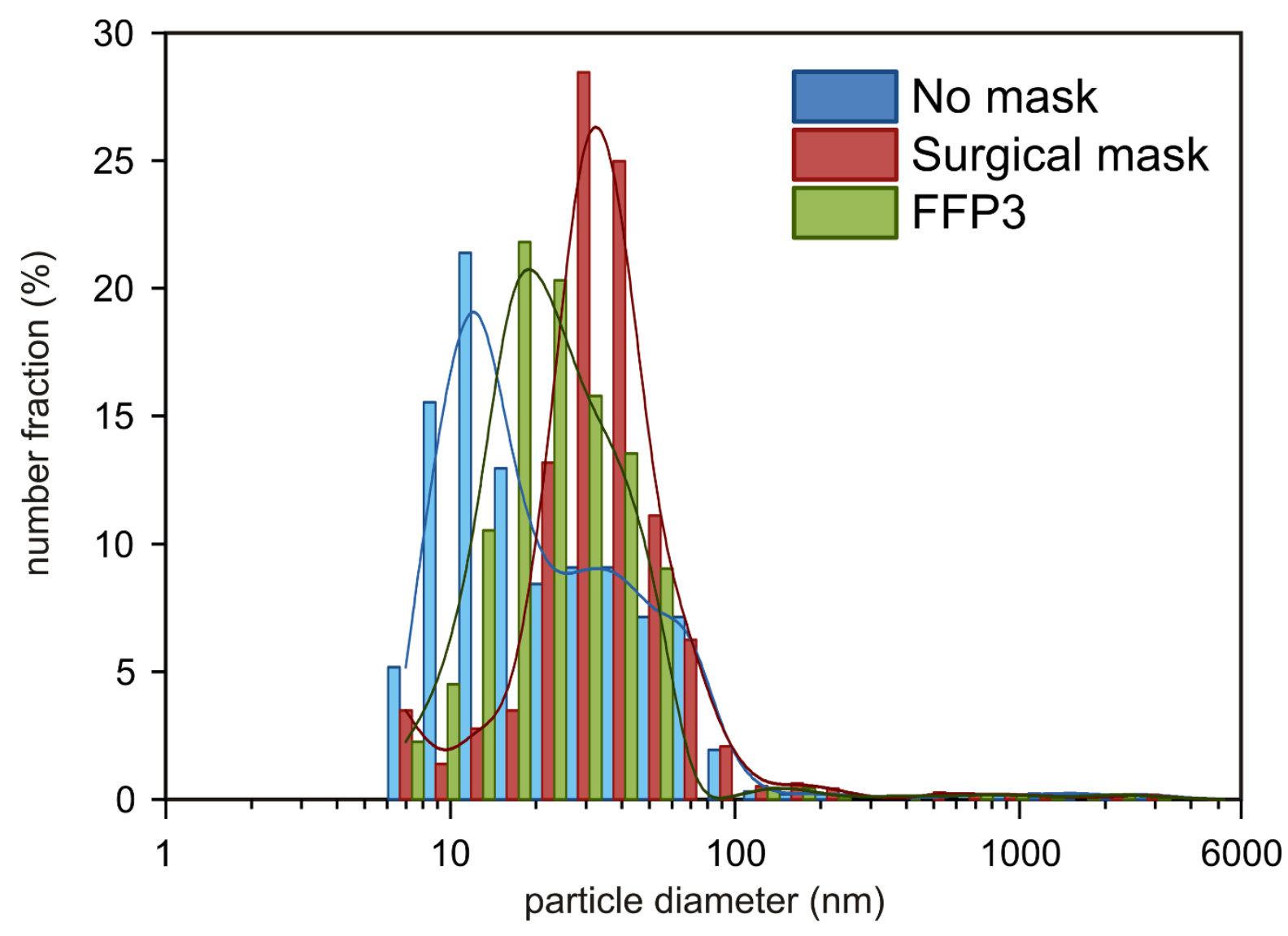




\section{FIGURE LEGENDS}

Fig. 1 Scheme of the experimental set-up.

Fig. 2 Ultra-morphological analysis of composite dust particles by transmission electron microscopy when no protection was applied and after particle penetration through surgical mask or FFP3 respirator. Particles of different sizes and shapes from micro- to nano-level were released during grinding composite material. Despite the use of either type of mask, single nano-sized filler particles could be collected.

Fig. 3 Particle number distribution of the composite dust determined by transmission electron microscopy image analysis. 